\title{
A seriously overlooked hemorrhage following paracentesis managed by trans-arterial embolization of the deep circumflex iliac artery: A case report
}

\author{
Mohammed H Habib ${ }^{1 *}$, Mohammed Hillis ${ }^{2}$ and Khaled H Alkhodari ${ }^{3}$ \\ ${ }^{1}$ Department of Cardiology and Cardiac Catheterization, Al-Shifa Hospital, Palestine \\ ${ }^{2}$ Department of Pediatric Cardiology, Al-Shifa Hospital, Palestine \\ ${ }^{3}$ The Islamic University of Gaza, Palestine
}

\begin{abstract}
\section{Introduction}

Paracentesis is a commonly used procedure to aspirate fluid from ascitic fluid in the peritoneal cavity [1]. The anterior abdominal wall contains many superficial blood vessels like the inferior epigastric arteries, superficial, and deep circumflex iliac arteries, and injury to one of them could lead to major bleeding [2]. Rupture of any of these arteries can lead to life-threatening complications or even death [3]. Here we report a case of right deep circumflex iliac artery rupture as a complication of paracentesis and its endovascular management.
\end{abstract}

A 72-year- old female patient with history of hepatitis $\mathrm{C}$ virus infection complicated by liver cirrhosis and decompensated liver disease. She had presented with abdominal distention and shortness of breath. This was gradually increased over 30 days with diffuse abdominal pain. Abdominal palpation was normal except for diminished liver span, fluid thrill, and shifting dullness. abdominal paracentesis at the right lower abdominal quadrant was done. After 24 hours of the paracentesis, the patient complaint from pain at the puncture site and there was ecchymosis occupying the anterior abdominal wall treated successfully by arterial embolization.

\section{Case report}

A 72 -year -old female patient diagnosed 1 year ago with hepatitis $\mathrm{C}$ virus infection complicated by liver cirrhosis and decompensated liver disease. She had presented with abdominal distention and shortness of breath for 30 days prior to admission. This was gradually increased over 30 days with diffuse abdominal pain (grade 6/10) without exacerbating or relieving factors; the pain was associated with constipation but without dysphagia, odynophagia, heartburn, nausea, vomiting, diarrhea, melena or hematemesis. On examination, the patient looked conscious, oriented, jaundiced in respiratory distress. Vital signs were abnormal as the temperature was $38.7^{\circ} \mathrm{C}$, blood pressure of $170 / 90$ $\mathrm{mmHg}$, pulse rate was $83 \mathrm{BPM}$, respiratory rate was 20 per minute, and oxygen saturation was $95 \%$ on room air. Both hands were normal, and the sclera was jaundiced bilaterally. The abdomen was distended with normal appearing umbilicus, and flanks bulging, there was no distended veins, no scratch marks, or spider angiomas. Abdominal palpation was normal except for diminished liver span, fluid thrill, and shifting dullness. Chest examination was normal except for dullness percussion note and decreased air entry in the right basal lung field. Lower limb examination revealed +4 bilateral pitting edema up to the knees.

Full laboratory work up was obtained and the results was as follows: (CBC: hemoglobin $11.2 \mathrm{~g} / \mathrm{dl}$, WBCs $4.110^{3} / \mathrm{mm}^{3}$, platelets count 82
$10^{3} / \mathrm{mm}^{3}$ ), urea $24 \mathrm{mg} / \mathrm{dl}$, creatinine $0.65 \mathrm{mg} / \mathrm{dl}$, INR 2.2, PT $23.3 \mathrm{sec}$, albumin $2.4 \mathrm{~g} / \mathrm{dl}$, AST $57 \mathrm{U} / \mathrm{L}$, ALT $36 \mathrm{U} / \mathrm{L}$, ALP $248 \mathrm{U} / \mathrm{L}$, random blood sugar $172 \mathrm{mg} / \mathrm{dl}$, (Electrolytes: $\mathrm{Na} 140 \mathrm{mmol} / \mathrm{l}$, K $3.7 \mathrm{mmol} / \mathrm{l}, \mathrm{Ca}$ $7.9 \mathrm{mg} / \mathrm{dl}$ ). Urine analysis was clear. Chest X-ray showed right sided pleural effusion.

Based on that data, abdominal paracentesis at the right lower abdominal quadrant was tried twice and was unsuccessful, on the third time, it was performed successfully and drained about $1500 \mathrm{cc}$ of clear peritoneal fluid. Ascitic fluid analysis revealed total white blood cells count of $800 \mathrm{PMN}$ cells $/ \mathrm{mm}^{3}$ 55\% neutrophils and 45\% lymphocytes. After 24 hours of the paracentesis, the patient complaint from pain at the puncture site and there was ecchymosis occupying the anterior abdominal wall associated with a superficial mass at the puncture site about $10 \times 10 \mathrm{~cm}$, well defined, non-mobile, non-tender, did not move with respiration (Figure 1).

After 48 hours of the paracentesis, the ecchymosis extended to cover the anterior abdominal wall, right anterior chest wall, and the right posterior abdominal wall, in addition to that, the hemoglobin level dropped from $11.2 \mathrm{~g} / \mathrm{dl}$ to $8 \mathrm{~g} / \mathrm{dl}$, and was management by packed red blood cells and fresh frozen plasma transfusion; also CT without contrast for the abdomen was requested and showed a superficial mass in the right lower abdominal quadrant measures about $9 \times 6.45 \times 15.5$ $\mathrm{cm}$ (Figure 2).

*Correspondence to: Mohammed Hussein Habib, Department of Cardiology and Cardiac Catheterization, Al-Shifa Hospital, Palestine, Tel: 00972599514060; E-mail: andre.remy@ch-perpignan.fr

Key words: anterior abdominal wall, liver cirrhosis, abdominal pain

Received: February 04, 2019; Accepted: February 18, 2019; Published: February 21, 2019 
Seven days after the paracentesis, and despite the supportive management the hemoglobin level was $10.4 \mathrm{~g} / \mathrm{dl}$, and the INR was 1.95 , PTT was 50 seconds, neither the mass nor the ecchymosis resolved, so the patient was referred to the interventional radiology department to undergo angiography and to control the bleeding. After cannulation of the left femoral artery by a 6 French guiding catheter, a 0.014 -inch wire inserted into the right deep circumflex artery, then a 2.7 French micro-catheter was inserted into the artery to inject 400 micro alcohol particles. Control angiography revealed a totally occluded right deep circumflex artery and the bleeding has stopped (Figure 3).

\section{Discussion}

Paracentesis is a bedside or clinic procedure used to aspirate fluid from the peritoneal cavity either for diagnostic or therapeutic goals [1]. Fluid accumulation in the peritoneal cavity has many causes, among the most important is liver cirrhosis, it is the most common cause for hospitalization in cirrhotic patients [4]. Cirrhotic patients with ascites have an increased risk to get their ascetic fluid infected spontaneously, known as spontaneous bacterial peritonitis (SBP), with an incidence of $14-25 \%$ [5] and it is a life-threatening infection as the mortality rate ranges $16-23 \%$ [6]. Therefore, this condition should be highly suspected in any cirrhotic patient with ascetic fluid presents with increased WBCs, worsening renal functions or others and a diagnostic paracentesis is required to rule in or out SBP [5].

Although paracentesis is a simple straight forward procedure, it has many complications some are life-threatening, among them is minor bleeding which constituted for $3.3 \%$ of the complications and about $1 \%$

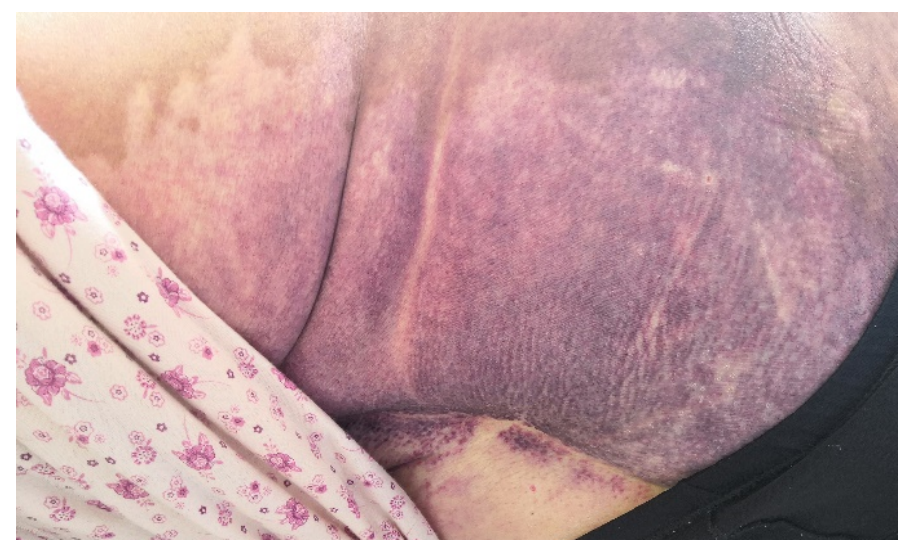

Figure 1. Lateral view of the patient flank shows a purple discoloration of flank, and gluteal skin
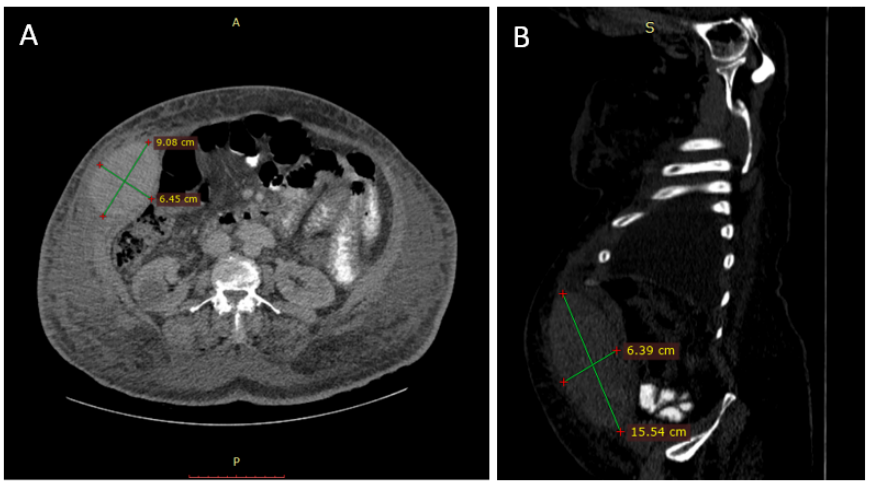

Figure 2. Non-contrast $\mathrm{CT}$ scan of the abdomen. Axial section (A) and sagittal section (B) shows a hyperdense well-localized mass in the right anterior abdominal wall measures about $9 \times 7 \times 15 \mathrm{~cm}$

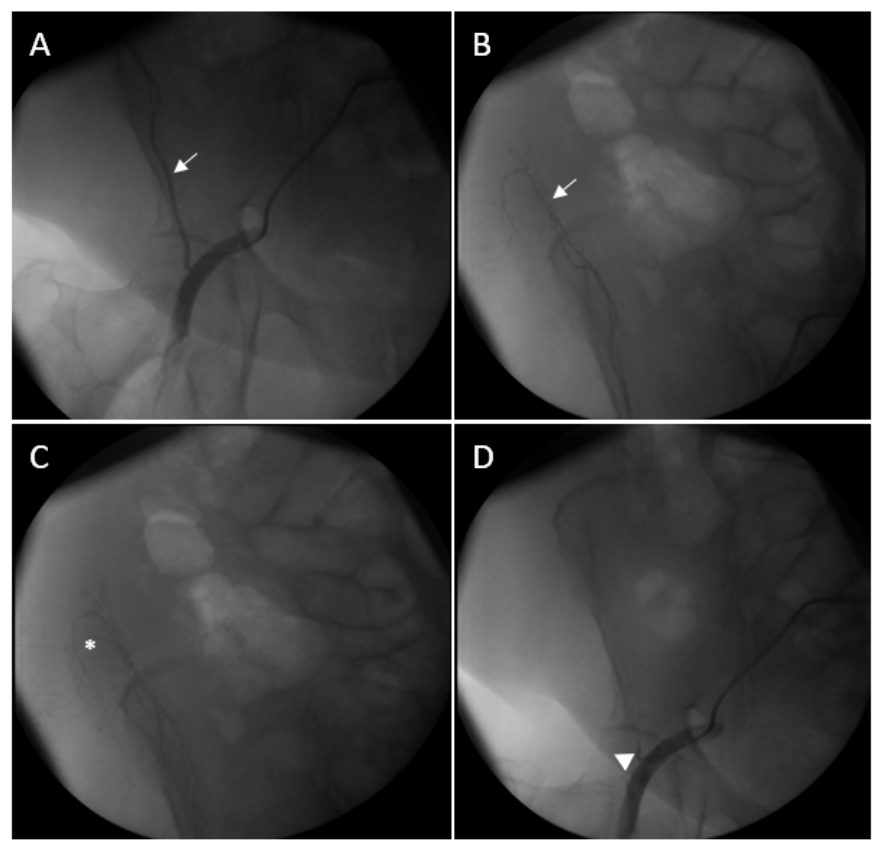

Figure 3. Serial angiography views show the deep circumflex iliac artery, arrow in (A) with its bleeding branches (B). There is contrast leak indicating hematoma marked with the asterisk in (C). Control angiography shows total occlusion of the deep circumflex iliac artery after embolization, arrowhead in (D)

was major bleeding and required blood transfusion [7]. Therefore, the puncture site for paracentesis should be chosen carefully as the anterior abdominal wall contains many superficial blood vessels among them are the inferior epigastric arteries, superficial, and deep circumflex iliac arteries, and injury to one of them could lead to major life-threatening bleeding [2] and could lead to death [3].

Rectus sheath hematoma is a blood collection between the anterior abdominal wall muscles fibers. It mostly presents as abdominal pain, abdominal wall mass, and abdominal tenderness $[8,9]$. There are many etiological factors for rectus sheath hematoma to occur, ranging from spontaneous bleeding to trauma, iatrogenic injury to an artery, and abnormal blood clotting [8]. Our mentioned case had an abnormal INR and an iatrogenic injury to the right deep circumflex iliac artery. The diagnosis could be missed as it only forms about $2 \%$ of the causes of the acute abdomen [10] and if not recognized early it will lead to circulatory collapse [11], unnecessary laparotomies and death [9]. Computed tomography (CT) scan is highly sensitive as can detect all the cases of the rectus sheath hematoma [8]. The management is mainly conservative, but invasive management is indicated if the patient is hemodynamically unstable or the hematoma continues to expand [8].

Despite that, the inferior epigastric artery is the most common artery to be injured during paracentesis $58.6 \%$ [12], injury to other arteries like the deep circumflex iliac artery should not be overlooked. In our case, the diagnosis was late, and the management was supportive, and the patient continued to deteriorate until she was managed by tansarterial embolization using alcohol particles.

To our knowledge, embolization of the deep circumflex iliac artery was done for the first time in our country, and about 9 times globally due to different reasons, but only the second time after paracentesis. Interestingly, the use of alcohol micro-particles is the first time to be reported in this case 


\section{Conclusion}

Paracentesis is an important diagnostic and therapeutic simple procedure for the management of intraperitoneal fluid collections. Despite that, it should be performed carefully correctly to prevent preventable complications. Among the life-threatening complications is the bleeding which should not be overlooked in any patient complaining from puncture site pain, swelling, or hematoma.

\section{Consent}

Verbal informed consent was obtained from the patient and her relatives for the publication of this report and any accompanying images.

\section{References}

1. Al-Osaimi AM, Manne V, Sundaram V (2014) Ascites and spontaneous bacterial peritonitis: Recommendations from two United States centers. Saudi J Gastroenterol 20: 279. [Crossref]

2. Runyon A (2018) Diagnostic and therapeutic abdominal paracentesis Waltham, MA: UpToDate Inc.

3. Seidler M, Sayegh K, Roy A, Mesurolle B (2013) A fatal complication of ultrasoundguided abdominal paracentesis. J Clin Ultrasound 41: 457-460. [Crossref]

4. Lucena MI, Andrade RJ, Tognoni G, Hidalgo R, De La Cuesta FS, et al. (2002) Multicenter hospital study on prescribing patterns for prophylaxis and treatment of complications of cirrhosis. Eur J Clin Pharmacol 58: 435-440. [Crossref]
5. Fagiuoli S, Colli A, Bruno R, Burra P, Craxi A, et al. (2013) Management of infections in cirrhotic patients: Report of a Consensus Conference. Dig Liver Dis 46: 204-212. [Crossref]

6. Singal K, Salameh H, Kamath PS (2014) Prevalence and in-hospital mortality trends of infections among patients with cirrhosis: A nationwide study of hospitalised patients in the United States. Aliment Pharmacol Ther 40: 105-112. [Crossref]

7. De Gottardi A, Thévenot T, Spahr L, Morard I, Bresson-Hadni S, et al. (2009) Risk of Complications After Abdominal Paracentesis in Cirrhotic Patients: A Prospective Study. Clin Gastroenterol Hepatol 7: 906-909. [Crossref]

8. Hatjipetrou A, Anyfantakis D, Kastanakis M (2015) Rectus sheath hematoma: a review of the literature. Int J Surg 13: 267-271. [Crossref]

9. Cherry WB, Mueller PS (2006) Rectus sheath hematoma: Review of 126 cases at a single institution. Medicine (Baltimore) 85: 105-110. [Crossref]

10. Klingler PJ, Wetscher G, Glaser K, Tschmelitsch J, Schmid T et al. (1999) The use of ultrasound to differentiate rectus sheath hematoma from other acute abdominal disorders. Surg Endosc 13: 1129-1134. [Crossref]

11. Sharafuddin MJ, Andresen KJ, Sun S, Lang E, Stecker MS, et al. (2001) Spontaneous extraperitoneal haemorrhage with hemodynamic collapse in patients undergoing anticoagulation: Management with selective arterial embolization. $J$ Vasc Interv Radiol 12: 1231-1234. [Crossref]

12. Sharzehi K, Jain V, Naveed A, Schreibman I (2014) Haemorrhagic Complications of Paracentesis: A Systematic Review of the Literature. Gastroenterol Res Pract: 1-6. [Crossref]

Copyright: (C2019 Habib MH. This is an open-access article distributed under the terms of the Creative Commons Attribution License, which permits unrestricted use, distribution, and reproduction in any medium, provided the original author and source are credited. 